\title{
LICENCIATURA E BACHARELADO EM EDUCAÇÃO FÍSICA: IMPACTOS NA FORMAÇÃO PROFISSIONAL NO ESTADO DE MINAS GERAIS
}

\author{
LICENCIATURA E BACHARELADO EM EDUCAÇÃO FÍSICA: IMPACTOS NA \\ FORMAÇÃO PROFISSIONAL NO ESTADO DE MINAS GERAIS
}

\author{
Bruna Beatriz da Rocha ${ }^{1}$, Fernanda Cristina dos Santos Coelho², Flaviana Alves \\ Toledo $^{3}$
}

1 Universidade Federal de Lavras - Programa de Pós-Graduação em Educação, Brasil, bruuna rocha1@hotmail.com

${ }^{2}$ Instituto Federal do Sudeste de Minas Gerais, Campus Barbacena, Brasil, fernanda.fcsc@hotmail.com 3 Instituto Federal do Sudeste de Minas Gerais, Campus Barbacena, Brasil. flaviana.toledo@ifsudestemg.edu.br

\author{
ART ICLE INFO \\ Article history: \\ Received 2018-07-03 \\ Accepted 2019-02-01 \\ Available online 2019-02-07
}

Palavras-chave: Formação profissional. Currículo. Educação física.

Keywords: Professional qualification. Curriculum. Physical education.

RESUMO. O presente estudo foi desenvolvido no Instituto federal Instituto Federal de Educação, Ciência e Tecnologia do Sudeste de Minas Gerais - Campus Barbacena, como Trabalho de Conclusão de Curso das discentes do curso de Licenciatura em Educação Física onde o objetivo foi analisar os currículos de formação de doze instituições de ensino superior em Educação Física no estado de Minas Gerais retiradas do sistema e-MEC, para compreender as semelhanças e diferenças entre os cursos de licenciatura $e$ bacharelado. Comparando as matrizes curriculares dos dois cursos, observamos que as diferenças são mínimas em relação aos conteúdos e cargas horárias com inclusão de disciplinas pedagógicas na licenciatura e de disciplinas de aperfeiçoamento no bacharelado. Assim, vemos que a oferta dos dois cursos tem como objetivo principal atender as demandas do capitalismo com a possibilidade da instituição privada ofertar dois diplomas, ampliando o tempo de permanência do aluno na mesma. Tendo em vista a grande proximidade em termos de conhecimentos ofertados nas duas formações, acreditamos que a restrição do campo de atuação profissional do licenciado é arbitrária e não condiz com as reais condições de atuar ou não em termos de formação. Observamos também que as transformações se dão em consonância com interesses privatistas ligados ao setor educacional e com as transformações do mundo do trabalho que passam a advogar a formação de um trabalhador de novo tipo.

ABSTRACT. The present study was developed at the Federal Institute of Education, Science and Technology of the Southeast of Minas Gerais - Campus Barbacena, as an undergraduate thesis of the undergraduate students of Physical Education Degree, where the objective was to analyze the training curriculum of twelve institutions of higher education in Physical Education in the state of Minas Gerais withdrawn from the e-MEC system, to understand the similarities and differences between licentiate and baccalaureate courses. Comparing the curricular matrices of the two courses, we observed that the differences are minimal in relation to the contents and workloads with the inclusion of pedagogical disciplines in the licentiate and of the subjects of improvement in the baccalaureate. Thus, the offer of two courses has as main objective to meet the demands of capitalism with the possibility of a private institution offering two degrees, increasing the length of time the student stays in it. Considering the close proximity in terms of the knowledge offered in both courses, we believe that the restriction of the professional field of the licensee is 
arbitrary and does not match the actual conditions of acting or not in terms of training. We also note that the transformations are in line with privatist interests linked to the educational sector and with the transformations of the world of work that advocate the formation of a new type of worker.

\section{Introdução}

A formação profissional em Educação Física é marcada inicialmente pelo caráter prático dado à disciplina e pela influência de médicos e militares, no entanto, desde sua origem esteve ligada à formação docente e esse quadro começa a se alterar a partir de 1987 com a possibilidade de formação em licenciatura e bacharelado. Essa transformação se dá em consonância com interesses privatistas ligados ao setor educacional e das práticas corporais e com as transformações do mundo do trabalho que passam a advogar a formação de um trabalhador de novo tipo.

As discussões sobre a fragmentação da profissão são agravadas a partir da década de 1990 e vão desembocar nas atuais resoluções aprovadas nos anos 2000.

Os homens se apropriam do ambiente transformando-o com o objetivo da manutenção da existência. Essa interação entre o indivíduo e o meio em que vive, é permeado pelo processo de trabalho. Nesse processo os homens além de construírem os objetos materiais necessários a sua sobrevivência, constroem também relações sociais e culturais que ganham diversos significados no decorrer da história (COIMBRA, 2009), sendo assim, a cultura corporal foi desenvolvida através do trabalho, fazendo conexão entre a natureza e o homem. A burguesia começou a se apoderar da cultura corporal desde a sua consolidação até os dias atuais.

Na década de 80, a formação profissional no Brasil se volta para empenhar os trabalhadores a gerar riquezas para a burguesia, o trabalhador desse período deveria possuir características polivalentes para atender a demanda do mercado capitalista. "No plano ideológico desloca-se a responsabilidade social do estado para o plano do individual. Já não há política de emprego e nem perspectiva de uma carreira, mas indivíduos empregáveis ou não, qualificáveis". (FRIGOTTO, 2001)

A Educação Física antes dessa época era uma disciplina indispensável para formação dos alunos, porém, perde um pouco de sua importância, a mesma é abordada como uma disciplina que não contribui imediatamente para o atual projeto de formação humana. O trabalho parte de uma investigação mais extensa que foi desenvolvido por um projeto de iniciação científica no Instituto Federal do Sudeste de Minas Gerais - Campus Barbacena, intitulado Formação Profissional em Educação Física: uma análise no Estado de Minas Gerais. Por compreendermos a importância do assunto e também o que ele acarreta na vida profissional dos docentes e discentes da área, decidimos pesquisar sobre o tema e para tal, 
analisamos os currículos de formação profissional de doze (12) instituições de ensino superior em Educação Física em Minas Gerais das quais tivemos acesso ao Projeto Político Pedagógico para assimilarmos as diferenças e semelhanças entre os currículos de licenciatura e bacharelado. Assim, será possível nos localizarmos sobre a nossa realidade e as nossas possibilidades.

\section{Fundamentação}

A Educação Física, foi introduzida pela primeira vez no Brasil em 1841, no antigo Imperial Colégio de Pedro II no Rio de Janeiro. Fundado em 1837, o intuito da escola era oferecer aos filhos da boa sociedade imperial uma formação secundária abrangente e distintiva, própria à elite daquele período.

Diversas obras como Coletivo de Autores (1992); Darido (2003; 2005); Betti (1991) e os Parâmetros Curriculares Nacionais (BRASIL, 1997), destacam que a concepção adotada (higienista e militarista) considerava a Educação Física como disciplina meramente prática, onde não precisava de teoria para fundamentá-la, fazendo com que não houvesse uma distinção entre a Educação Física e a instrução militar, assim, não sendo necessário dominar conhecimentos além daqueles inerentes ao de um ex praticante (FERNANDES, 2009) para ensiná-la. Somente em 1941, com a criação Escola Nacional de Educação Física e Desportos (ENEFD), passa-se a exigir o diploma de Licenciado para exercício da profissão.

A partir da década de 1960, há um crescimento expressivo de instituições formadoras em Educação Física, com viés tecnicista e formação voltada predominantemente para atuação docente. Com a expansão do mercado de trabalho em Educação Física nas áreas não-escolares a partir do ano de 1980, o Conselho Federal de Educação aprovou em 1987 a resolução n.03/87, que possibilitou a oferta do curso de bacharelado na área e toda formação profissional passou a ser realizada em quatro anos (SOUZA NETO et al, 2004). Apesar disso, grande parte das instituições permaneceram com a formação em licenciatura.

A profissão Educação Física no Brasil é regulamentada em 1998, momento em que foi criado o Conselho Federal de Educação Física - CONFEF através da Lei no 9696/98. Sob ingerência desse Conselho em articulação com ao CNE foi aprovado o Parecer CNE/CES 0138/2002 que reafirma a divisão da Educação Física em licenciatura e bacharelado (BRASIL, 2002). Nozaki (2004) destaca que o parecer não representa um consenso na área da Educação Física: grupos posicionam-se contrários a este documento, especialmente pelo reconhecimento do retrocesso que o mesmo representa para a área. As ações resistivas referem-se ao posicionamento dos dirigentes das 
escolas de Educação Física, do Colégio Brasileiro de Ciências do Esporte (CBCE), do Movimento Nacional contra a Regulamentação do Profissional de Educação Física (MNCR) e da Executiva Nacional dos Estudantes de Educação Física (ExNEEF).

Conforme indica Nozaki (2003):

Os dirigentes das escolas de Educação Física, no II Fórum Nacional das Instituições de Ensino Superior em Educação Física (2002), dirigem-se ao MEC e ao CNE e reivindicam a não publicação da resolução decorrente do Parecer CNE/CES 0138/2002; ademais, argumentam sobre a "[...] descaracterização da tradição histórica da formação acadêmica e profissional da educação física, reduzindo-a ao campo de intervenção sob uma concepção restrita de saúde.

Após a validação da resolução CNE/CES 07/2044 que trata dos conteúdos específicos à graduação em Educação Física, o CREF passou a criar meios de impedir a atuação dos licenciados em áreas não escolares como academias, clubes entre outros, restringindo-os à escola alegando que a Licenciatura deveria basear-se somente na resolução CNE/CP n01/2002 e 02/2002, que institui as diretrizes curriculares para a formação de professores para a educação básica e carga horária mínima em todas as áreas e a resolução CNE/CES n 07/2004 supracitada deveria orientar a formação nos cursos de bacharelado (CREF 4/SP).

Rodrigues (2012) defende ainda que, independente do campo de atuação profissional, a formação docente é a balizadora da formação em Educação Física:

(...) não tem sustentação do ponto de vista epistemológico a divisão da formação em educação física, e que ela se pauta numa interpretação equivocada acerca dos campos de intervenção da Educação Física, como se o professor da escola, do lazer, do campo da promoção da saúde ou do campo da estética, não se valesse nas várias situações, da docência que se expressa no trabalho pedagógico do trato específico de um determinado campo de conhecimento (2012, p.85).

O ensino superior vem crescendo consideravelmente no campo da Educação Física, os dados mostram um maior interesse das instituições privadas nesta formação e para além dela, vislumbrando a expansão de um mercado vinculado às práticas corporais como observado por SILVA (2009).

Ele ainda aponta que este novo regime educacional que divide este campo específico, não só desprestigia e desvaloriza a luta dos setores progressistas da área por uma identidade fundamentada numa formação generalista e competente, construída à 
compreensão do direito de acesso a cultura corporal, como reforça um processo de alienação na formação para o trabalho, reforçando a divisão entre teoria e prática, público e privado, formação ampliada e formação especializada, legitimando o discurso em voga e reforçando uma trajetória histórica conservadora que está em curso no país há tempos. A educação, como processo de formação humana, produção e socialização do conhecimento sistematizado pela humanidade, passa a estar cada vez mais constituída a partir dos discursos da eficácia, lucro e competitividade provenientes do mundo econômico político.

O debate quanto á formação profissional em Educação Física no Brasil está presente desde a criação de seus primeiros cursos na primeira metade do século XX e em determinadas épocas da história aparece de forma mais intensa. A fragmentação da formação e a tentativa de cerceamento da atuação dos licenciados em educação física no Brasil são a motivação e justificativa de nos debruçarmos sobre os estudos da atual condição que se encontram os cursos de formação em Educação Física em Minas Gerais.

\section{Método}

O referencial teórico reivindicado por essa pesquisa se assenta à luz do materialismo histórico dialético por entendermos que o referencial teórico não se trata apenas de um amontoado de autores fragmentados que se debruçam sobre o tema em questão, mas, fundamentalmente, como uma forma de se entender a realidade e a ciência.

Daqui depreendemos o entendimento da não existência da neutralidade axiológica e que, portanto, antes de se propor qualquer tipo de pesquisa, deve-se ter em pauta a partir de que concepção de mundo se fala.

Sobre o referencial teórico, partimos de Kosik (1976):

Conhecemos o mundo, as coisas, os processos somente na medida em que os "criamos", isto é, na medida em que os reproduzimos espiritualmente e intelectualmente. Essa reprodução espiritual da realidade só pode ser concebida como um dos muitos modos de relação prático-humana com a realidade, cuja dimensão mais essencial é a criação da realidade humanosocial. Sem a criação da realidade humano-social não é possível sequer a reprodução espiritual e intelectual da realidade (p.226- grifos do autor).

Para tanto, o materialismo histórico dialético sustenta como critério de verdade a práxis social, a qual deve ser analisada á luz de categorias ligadas ao método, como a totalidade, a contradição, a mediação, a própria práxis entre outras. 
Traçamos assim um diálogo com autores e trabalhos clássicos da área entendendo a sua contribuição para o avanço do conhecimento, como também nos debruçamos sobre trabalhos mais recentes, a fim de termos subsídios teóricos consistentes sobre a nossa temática.

Esse trabalho se pauta em uma análise qualitativa que, como afirma TURATO (2003), caracteriza-se principalmente pela profundidade de análise, a pesquisa de natureza qualitativa se preocupa basicamente com significados, opiniões e representações acerca de determinado fenômeno.

Utilizamos como material empírico o projeto pedagógico de doze instituições que ofertam os cursos de licenciatura e bacharelado em Educação Física no estado de Minas Gerais. Desse material buscamos extrair o tipo de formação, a modalidade de oferta, categoria administrativa e o mercado profissional visado por cada curso.

Posteriormente, selecionamos os projetos pedagógicos das cinco instituições que ofertam simultaneamente os cursos de Licenciatura e Bacharelado objetivando de comparar as matrizes curriculares sob os aspectos das disciplinas ofertadas e carga horária destinada a elas.

\section{Resultados e Discussão}

Em análise ao sistema eletrônico e-MEC realizado em novembro de 2015, verificamos que haviam cadastradas 93 (noventa e três) Instituições que ofertam curso de Educação Física no Estado de Minas Gerais, das quais analisamos somente 12 do qual tivemos acesso ao Projeto Político Pedagógico. Apesar de várias tentativas via e-mail e telefone, não obtivemos êxito com as demais instituições.

Nessa análise observamos que das 12 (doze) instituições pesquisadas, 3 (três) oferecem o curso de licenciatura, 5 (cinco) oferecem ambas as modalidades (Licenciatura e Bacharelado) e 4 (quatro) oferecem somente a modalidade bacharelado.

${ }^{1} \mathrm{~A}$ Resolução CNE/CP 02/2002 ${ }^{1}$ responsável por instituir a duração e a carga horária dos cursos de licenciatura, de graduação plena, de formação de professores da Educação Básica em nível superior prevê que a duração mínima dos cursos de licenciatura é de três anos, a carga horária mínima do curso é de 2800 horas e o estágio na educação

\footnotetext{
${ }^{1}$ A resolução descrita foi vigente durante o tempo de pesquisa para o presente trabalho e atualmente foi substituída pela Resolução 02/2015 onde todos os cursos de licenciatura deverão se adequar até metade do ano de 2018.
} 
básica tem que cumprir no mínimo 400 horas. Pudemos observar que todos os cursos de licenciatura estão de acordo com a mesma, indo além da carga horária proposta de 2800 (duas mil e oitocentas) horas além de obedecerem às horas de estágio propostas, cumprindo às 400 horas recomendadas. Dentre essas instituições, destacamos o Instituto Federal do Sudeste de Minas campus Barbacena, que cumpre a carga horária prevista no estágio na educação básica e ainda exige o estágio no espaço não-escolar, com um total de 60 (sessenta horas).

Já a Resolução CNE/CP 04/2009 dispõe que a carga horária mínima de duração dos cursos de graduação em Educação Física, bacharelados, na modalidade presencial é de 3200 horas distribuídos em quatro anos e os estágios, juntamente com as atividades complementares não deverão exceder a $20 \%$ (vinte por cento) da carga horária total do curso, salvo nos casos de determinações específicas contidas nas respectivas Diretrizes Curriculares. Assim, todos os cursos de bacharelado analisados atendem à determinação prevista, exceto o da Universidade Federal de Ouro Preto que no momento da pesquisa apresentava carga horária de 2855 horas para a integralização do curso, inferior às 3200 horas previstas.

Ao analisarmos o perfil de egresso, buscamos verificar qual o apontamento de cada instituição em relação ao mercado de trabalho e todas as instituições que ofertam a licenciatura afirmam que o mercado de trabalho para o formando é na educação básica, exceto o Instituto Federal de Ciências e Tecnologia - campus Barbacena, que afirma que o campo de atuação de seus formandos é tanto na área escolar como na área não escolar. As instituições que ofertam o bacharelado afirmam que o campo de atuação de seus formandos é somente na área não escolar.

Embora não tenhamos encontrado evidências legais da limitação do campo de atuação dos professores de Educação Física formados nos cursos de licenciatura, parece haver uma tendência das Instituições que ofertam esse curso em apontar em seus perfis de egresso uma atuação pautada na Educação Básica.

Buscando em documentos que relatam sobre a atuação profissional no campo não-escolar, vemos que o único critério para se exercer livremente a profissão é a inscrição nos Conselhos Regionais de Educação Física (CONFEF/CREF) e possuir o diploma obtido em curso de Educação Física oficialmente autorizado ou reconhecido como prevê a Lei 9.696/98 em seu artigo $2^{\circ}$, inciso I, sem a explicitação se é um diploma de licenciatura ou bacharelado e sim o diploma obtido em curso de Educação Física.

A lei 9696/98 que regulamenta a profissão Educação Física prevê ainda em seu artigo $3^{\circ}$ : 
mar, supervisionar, dinamizar, dirigir, organizar, avaliar e executar trabaIhos, programas, planos e projetos, bem como prestar serviços de auditoria, consultoria e assessoria, realizar treinamentos especializados, participar de equipes multidisciplinares e interdisciplinares e elaborar informes técnicos, científicos e pedagógicos, todos nas áreas de atividades físicas e do desporto.

Com base nesses dados não consideramos razoável a restrição da atuação profissional dos Licenciados em Educação Física, podendo exercer livremente a sua profissão em todos os campos de atuação da área previstas no art. 3ํ da Lei nº 9.696/98, o que inclui em sua interpretação a atuação não só em colégios e universidades, mas também em academias, clubes e em outras áreas abrangentes².

Para reforçar a tese de que o licenciado pode atuar nos diferentes espaços que abrange a Educação Física, trouxemos um parecer do Conselho Nacional de Educação baseada em afirmações do Ministério da Educação que reconhece a possibilidade de o licenciado em Educação Física exercer a sua profissão, sem restrições, como mostra alguns trechos da decisão da Câmara Superior de Educação (vinculada ao CNE/MEC), proferida no parecer no 400/2005 CNE/CES de 22/11/2005:

(...) IV - É admissível que dois cursos que conduzam à licenciatura em Educação Física ensejem registros em campos de atuação diversos?Resposta: Reitere-se aqui que todas as licenciaturas em Educação Física no Brasil estão sujeitas ao cumprimento da Resolução CNE/CES no 1/2002. Portanto, todos os licenciados em Educação Física têm os mesmos direitos, não devendo receber registros em campos de atuação diferentes.

(...) Portanto, está definido que (1) a competência para legislar sobre as qualificações profissionais requeridas para o exercício de trabalho que exija o atendimento de condições específicas é privativa da União, não sendo cabível a aplicação de restrições que eventualmente sejam impostas por outros agentes sociais; (2) a Lei Federal n 9.696/1998 estabelece as competências do profissional de Educação Física e a condição requerida para o exercício profissional das atividades de Educação Física; (3) esta condição é o registro regular nos Conselhos Regionais de Educação Física; (4) a inscrição nestes Conselhos, para aqueles que se graduaram ou vierem a se graduar após a edição da Lei n 9.696/1998, é restrita àqueles que possuem diploma obtido no país, em curso reconhecido, ou no exterior, e posteriormente revalidado; (5) a legislação educacional, e, em especial a Lei $n^{\circ}$

\footnotetext{
2 Essa tentativa de cerceamento da atuação nos campos não escolares se deu através da resolução interna do próprio CONFEF anos após a regulamentação.
} 
9.394/1996, que estabelece as Diretrizes e Bases da Educação Nacional, não discrimina cursos de Licenciatura entre si, mas apenas determina que todos os cursos sigam as Diretrizes Curriculares Nacionais; (6) enfim, todos os portadores de diploma com validade nacional em Educação Física, tanto em cursos de Licenciatura quanto em cursos de Bacharelado, atendem às exigências de graduação previstas no inciso I do art. $2^{\circ}$ da Lei $n^{\circ}$ 9.696/1998. Desta forma, não tem sustentação legal - e mais, é flagrantemente inconstitucional - a discriminação do registro profissional e, portanto, a aplicação de restrições distintas ao exercício profissional de graduados em diferentes cursos de graduação de Licenciatura ou de Bacharelado em Educação Física, através de decisões de Conselhos Regionais ou do Conselho Federal de Educação Física. Portanto, a delimitação de campos de atuação profissional em função da modalidade de formação, introduzida pelo artigo 30 da citada Resolução CONFEF no 94/2005, assim como as eventuais restrições dela decorrentes, que venham a ser aplicadas pelos ConseIhos Regionais de Educação Física, estão em conflito com o ordenamento legal vigente no país.

Para acrescentar, destacamos que a LDB - Lei de Diretrizes e Bases da Educação Nacional (Lei 93.394/96), em seu art. 62, não impede o licenciado de atuar fora das escolas, mas prevê que apenas ele poderá atuar dentro delas, pois se comparado ao bacharelado, é o único curso com formação pedagógica no seu currículo e isso o habilita para essa atuação na educação básica, como se vê da transcrição da norma:

Art. 62. A formação de docentes para atuar na educação básica far-se-á em nível superior, em curso de licenciatura, de graduação plena, em universidades e institutos superiores de educação, admitida, como formação mínima para o exercício do magistério na educação infantil e nas quatro primeiras séries do ensino fundamental, a oferecida em nível médio, na modalidade Normal (LEI № 9.394/96).

Baseando nos dados acima, podemos perceber que as exigências são necessárias ao trabalhar na docência na educação básica e não impeditivas de atuação em outras áreas.

A defesa da fragmentação da profissão pelos setores privatistas juntamente com o sistema CONFEF/CREF, preconiza que a formação em áreas específicas, em detrimento de uma formação generalista, atenderá de forma mais imediata às exigências do mercado de trabalho, sem, no entanto se preocupar com as condições desse trabalho na atual fase de desenvolvimento capitalista.

Diante de tal polêmica sobre a formação em Licenciatura e Bacharelado e as áreas de atuação profissional, buscamos analisar e comparar as matrizes curriculares dos 
cursos de educação física das instituições que oferecem simultaneamente as duas formações, totalizando cinco instituições.

Verificamos que em todas as instituições, as disciplinas são classificadas e divididas em duas formações: formação específica e formação ampliada, sendo que a formação específica são as disciplinas que abrangem os conhecimentos que identificam a Educação Física, tais como as culturais do movimento humano; as técnico-instrumentais e as didático- pedagógicas. A formação ampliada por sua vez, se caracteriza pelas disciplinas que abrangem as seguintes dimensões do conhecimento: relação ser humanosociedade; biológicas do corpo humano e produção do conhecimento científico e tecnológico. Assim, utilizamos esses critérios para representar os resultados da nossa pesquisa.

$\mathrm{Na}$ primeira instituição analisada (Universidade Federal de Lavras), observamos em sua formação específica na dimensão dos aspectos culturais do desenvolvimento humano, uma similaridade entre as disciplinas e carga horária de 61,53\% em relação a ambos os cursos, já na dimensão dos aspectos técnico-instrumentais, o percentual de disciplinas iguais é de $91,48 \%$ e por fim uma similaridade que representa $62,06 \%$ na dimensão dos aspectos didático-pedagógicos. Já em relação à formação ampliada, a similaridade das disciplinas e carga horária é de $88,88 \%$ na dimensão relação ser humano sociedade, de 54,83\% na dimensão biológicas do corpo humano, de 62,06\%na dimensão da produção do conhecimento científico e tecnológico e há uma igualdade de $100 \%$ na dimensão dos conhecimentos sobre equipamentos e materiais que é uma dimensão própria da instituição.

Ao analisar a Universidade Federal de Ouro Preto, os dados também apontam uma grande similaridade entre as disciplinas em ambas as formações (Licenciatura e Bacharelado), com os seguintes valores: $100 \%$ de igualdade nas disciplinas e carga horária das dimensões relação ser-humano sociedade e produção do conhecimento científico e tecnológico e ainda $80,32 \%$ na dimensão biológicas do corpo humano que representam a formação ampliada da instituição. A formação específica por sua vez, oferece $77,27 \%$ de disciplinas idênticas na dimensão dos aspectos culturais do desenvolvimento humano; $75 \%$ na dimensão dos aspectos técnico-instrumentais e por fim, $74,46 \%$ na dimensão dos aspectos didático-pedagógicos.

O Instituto Federal de Ciências e Tecnologia do Sul de Minas Gerais - Campus Muzambinho apresenta similaridade de $100 \%$ nas disciplinas e carga horária em todas as dimensões da formação ampliada e em sua formação específica, essa igualdade é de $80 \%$ na dimensão dos aspectos culturais do desenvolvimento humano; de $38,86 \%$ na dimensão 
dos aspectos técnico-instrumentais e de 9,06 na dimensão dos aspectos didáticopedagógicos.

Finalizando a nossa análise com a Universidade Federal de Viçosa e a Universidade Federal dos Vales do Jequitinhonha e Mucuri na qual destacamos que possuem o mesmo Projeto Político Pedagógico, quando analisada a formação específica, verificamos que em relação à dimensão dos aspectos culturais do desenvolvimento humano as disciplinas são equivalentes em um total de 76,53\%; na dimensão dos aspectos técnico-instrumentais esse valor é de $71,42 \%$ e na dimensão dos aspectos didático-pedagógicos as disciplinas têm uma similaridade de 70,96\%. Por fim, em sua formação ampliada, a porcentagem de similaridade entre os dois cursos é de $11,42 \%$ na dimensão relação ser-humano sociedade; de $83,33 \%$ na dimensão biológicas do corpo humano e de $60 \%$ na produção do conhecimento científico e tecnológico. Apresentamos nos quadros abaixo, de forma mais simplificada o descrito acima.

Quadro 1 - Percentual de similaridade entre disciplinas e carga horária dos cursos de licenciatura e bacharelado em educação física na formação ampliada.

\begin{tabular}{|c|c|c|}
\hline Instituição & $\begin{array}{|lc|}\begin{array}{l}\text { Dimensão } \\
\text { conhecimento }\end{array} & \text { do } \\
\end{array}$ & $\begin{array}{ll}\begin{array}{l}\text { Percentual } \\
\text { similaridade (\%) }\end{array} & \text { de } \\
\end{array}$ \\
\hline \multirow[t]{4}{*}{$\begin{array}{lll}\begin{array}{l}\text { Universidade } \\
\text { Lavras }\end{array} & \text { Federal } & \text { de } \\
& & \end{array}$} & $\begin{array}{lll}\begin{array}{l}\text { Relação } \\
\text { sociedade }\end{array} & \text { ser- } & \text { humano }\end{array}$ & 61,53 \\
\hline & Biológicas do corpo humano & 91,48 \\
\hline & $\begin{array}{l}\text { Produção do conhecimento } \\
\text { científico e tecnológico }\end{array}$ & 62,06 \\
\hline & $\begin{array}{l}\text { Conhecimentos sobre } \\
\text { equipamentos e materiais }\end{array}$ & 100 \\
\hline \multirow[t]{3}{*}{$\begin{array}{lll}\text { Universidade } & \text { Federal } & \text { de } \\
\text { Ouro Preto } & & \end{array}$} & $\begin{array}{lll}\begin{array}{l}\text { Relação } \\
\text { sociedade }\end{array} & \text { ser- } & \text { humano } \\
\end{array}$ & 100 \\
\hline & Biológicas do corpo humano & 80,32 \\
\hline & $\begin{array}{l}\text { Produção do conhecimento } \\
\text { científico e tecnológico }\end{array}$ & 100 \\
\hline \multirow{3}{*}{$\begin{array}{l}\text { Instituto Federal de Ciências } \\
\text { e Tecnologia do Sul de } \\
\text { minas Gerais- } \\
\text { Muzambinho }\end{array}$} & $\begin{array}{lll}\begin{array}{l}\text { Relação } \\
\text { sociedade }\end{array} & \text { ser- } & \text { humano } \\
\end{array}$ & 100 \\
\hline & Biológicas do corpo humano & 100 \\
\hline & $\begin{array}{l}\text { Produção do conhecimento } \\
\text { científico e tecnológico }\end{array}$ & 100 \\
\hline \multirow{3}{*}{$\begin{array}{llr}\text { Universidade } & \text { Federal de } \\
\text { Viçosa e } & \text { Universidade } \\
\text { Federal dos } & \text { Vales do } \\
\text { Jequitinhonha e Mucuri }\end{array}$} & Relação & 11,42 \\
\hline & Biológicas do corpo humano & 83,33 \\
\hline & $\begin{array}{l}\text { Produção do conhecimento } \\
\text { científico e tecnológico }\end{array}$ & 60 \\
\hline
\end{tabular}

Fonte: Os Autores (2017) 
Quadro 2 - Percentual de similaridade entre disciplinas e carga horária dos cursos de licenciatura e bacharelado em educação física na formação específica.

\begin{tabular}{|c|c|c|}
\hline Instituição & $\begin{array}{l}\text { Dimensão } \\
\text { conhecimento }\end{array}$ & \begin{tabular}{|ll} 
Percentual & de \\
similaridade (\%) &
\end{tabular} \\
\hline \multirow[t]{3}{*}{$\begin{array}{l}\text { Universidade } \\
\text { Lavras }\end{array}$} & $\begin{array}{l}\text { Aspectos culturais do } \\
\text { desenvolvimento humano }\end{array}$ & 88,88 \\
\hline & \begin{tabular}{|ll} 
Aspectos & técnico- \\
instrumentais &
\end{tabular} & 54,83 \\
\hline & $\begin{array}{ll}\text { Aspectos } & \text { didático- } \\
\text { pedagógicos } & \end{array}$ & 62,06 \\
\hline \multirow[t]{3}{*}{$\begin{array}{lll}\text { Universidade } & \text { Federal } & \text { de } \\
\text { Ouro Preto } & & \end{array}$} & $\begin{array}{l}\text { Aspectos culturais do } \\
\text { desenvolvimento humano }\end{array}$ & 77,27 \\
\hline & $\begin{array}{|ll|}\text { Aspectos } & \text { técnico- } \\
\text { instrumentais } & \\
\end{array}$ & 75 \\
\hline & $\begin{array}{l}\text { Aspectos } \\
\text { pedagógicos }\end{array}$ & 74,46 \\
\hline \multirow{3}{*}{$\begin{array}{l}\text { Instituto Federal de Ciências } \\
\text { e Tecnologia do Sul de } \\
\text { minas Gerais- } \text { Campus } \\
\text { Muzambinho }\end{array}$} & $\begin{array}{l}\text { Aspectos culturais do } \\
\text { desenvolvimento humano }\end{array}$ & 80 \\
\hline & $\begin{array}{|ll|}\begin{array}{l}\text { Aspectos } \\
\text { instrumentais }\end{array} & \text { técnico- } \\
\end{array}$ & 38,86 \\
\hline & $\begin{array}{|ll|}\text { Aspectos } & \text { didático- } \\
\text { pedagógicos } & \\
\end{array}$ & 9,06 \\
\hline \multirow{3}{*}{\begin{tabular}{llr}
\multicolumn{2}{l}{ Universidade } & Federal \\
Viçosa e de \\
Federal dos & Universidade \\
Jequitinhonha e & Mucuri
\end{tabular}} & $\begin{array}{l}\text { Aspectos culturais do } \\
\text { desenvolvimento humano }\end{array}$ & 76,53 \\
\hline & \begin{tabular}{|ll} 
Aspectos & técnico- \\
instrumentais & \\
\end{tabular} & 71,42 \\
\hline & $\begin{array}{l}\text { Aspectos } \\
\text { pedagógicos }\end{array}$ & 70,96 \\
\hline
\end{tabular}

Fonte: Os Autores (2017)

Baseando nas análises acima, verificamos que há uma média de $80,78 \%$ de similaridade entre as disciplinas da formação ampliada e de $64,94 \%$ nas disciplinas da formação específica, resultando em uma média de $72,86 \%$ de igualdade de disciplinas e carga horária de ambos os cursos (licenciatura e bacharelado). Essa análise nos mostra que as duas formações são muito próximas quanto aos conhecimentos e práticas. Observamos diferenças em relação às formações que, estão ligadas às áreas didáticopedagógicas ofertadas nos cursos de licenciatura e na maioria dos casos em disciplinas de aprofundamento no bacharelado, de conteúdos que foram abordados anteriormente em ambos os cursos como notamos claramente quando analisamos a Universidade Federal de Lavras. Nessa instituição, além de os alunos terem a disciplina de esportes coletivos e esportes individuais nas duas formações, no bacharelado eles ainda terão o Aprofundamento em esportes coletivos I, II, III e IV; Aprofundamento em esportes individuais I, II, III e IV. Silva (2011, p. 82) ao analisar os cursos de licenciatura e 
bacharelado ofertados em uma instituição de ensino superior apontou dados semelhantes aos encontrados nas instituições analisadas nessa pesquisa e concluiu que "os dados demonstram uma clara dificuldade da instituição de ensino em definir as concepções, objetivos e perfis profissionais do seu curso, que realmente diferencie a licenciatura do bacharelado e que realmente se faça refletir na suas matrizes curriculares".

Segundo ele, esse fato se dá pela falta de clareza das resoluções que norteiam a formação profissional em Educação Física, não garantindo aos cursos uma identidade própria. Essa falta de identidade e a similaridade da formação ofertada nos cursos de licenciatura e bacharelado levam-nos a questionar a razoabilidade da restrição da atuação profissional nos graduados em licenciatura nos campos não-escolares.

O campo da educação física tem buscado se reorganizar no sentido de rever as diretrizes curriculares propostas para sua formação em busca de uma formação unitária, centrada na licenciatura, entendendo que a atuação docente deve ser o eixo balizador da formação, seja para atuação nos campos escolares ou não-escolares. A minuta do projeto de resolução que Institui Diretrizes Curriculares Nacionais para o curso de graduação em Educação Física, Licenciatura, discutida em audiência pública no dia 11 de dezembro de 2015 prevê:

Art. 3‥ Os cursos de Educação Física deverão assegurar uma formação generalista, humanista e crítica, qualificadora da intervenção acadêmicoprofissional, fundamentada no rigor científico, na reflexão filosófica e na conduta ética.

Art. 7ํ. Os cursos de Bacharelado em Educação Física atualmente existentes entrarão em regime de extinção, a partir do ano letivo seguinte à publicação desta Resolução.

Entendemos que essa minuta, se aprovada será um avanço para a formação profissional em Educação Física e findará a discussão que permeia hoje a atuação do professor de Educação Física com a fragmentação da sua formação e conseqüente restrição do seu campo de atuação profissional.

\section{Considerações Finais}

Com esse estudo foi possível identificar que os cursos de bacharelado e licenciatura em Educação Física estão interligados entre questões profissionais e acadêmicas. Comparando as matrizes curriculares dos cursos de licenciatura e bacharelado em Educação Física, observamos que as diferenças são mínimas em relação aos conteúdos e cargas horárias. As formações ampliadas e específicas são representadas pelas mesmas disciplinas em ambos os cursos, a única diferença é a 
inclusão de disciplinas de cunho pedagógico na licenciatura e de disciplinas de aperfeiçoamento no bacharelado que servem como eletivas para a licenciatura. Compreendemos assim, que a oferta dos dois cursos tem como objetivo principal atender as demandas do capitalismo com a possibilidade da instituição privada ofertar dois diplomas, ampliando o tempo de permanência do aluno na mesma.

Tendo em vista a grande proximidade em termos de conhecimentos ofertados nos cursos de licenciatura e bacharelado, acreditamos que a restrição do campo de atuação profissional do licenciado é arbitrária e não condiz com as reais condições de atuar ou não em termos de formação.

As atuais discussões acerca da formação única pautada na licenciatura e na atividade docente como principal característica da Educação Física, pode representar um avanço na formação profissional da área e na atuação dos professores formados que hoje se encontram fragmentados em campos escolares e não-escolares e também um avanço na organização da categoria na luta pela regulamentação do seu trabalho, fato hoje permeado pela fragmentação do curso que faz com que os formados em bacharelado e licenciatura se dividam, dividindo assim a Educação Física.

Por fim, a pesquisa nos deixou mais próximos quanto a nossa realidade, notamos que o debate sobre a formação profissional em Educação Física deve ser contínuo, já que o mesmo tem influência no sistema em que estamos inseridos.

\section{REFERÊNCIAS}

BENITES, Larissa Cerignoni; NETO, Samuel de Souza; HUNGER, Dagmar. O processo de constituição histórica das diretrizes curriculares na formação de professores de Educação Física. Educação e Pesquisa, São Paulo, v.34, n.2, p. 343-360, 2008.

Brasil. Lei no 9.394, de 20 de dezembro de 1996. Estabelece as diretrizes e bases da educação nacional. Diário Oficial [da República Federativa do Brasil], Brasília, DF, v. 134, n. 248, 23 dez. 1996. Seção I, p. 27834-27841.

Brasil. Lei № 9.696, de $1^{\circ}$ de setembro de 1998. Dispõe sobre a regulamentação da profissão de educação física e cria os respectivos conselho federal e conselhos regionais de educação física. Diário Oficial da União, Brasília, DF, 2 out. 1998. Seção 1. Conselho federal de educação física. Disponível em: http://www.confef.org.br/extra/crefs/. Acesso em: 22 jun de 2017.

COIMBRA,Tatiane Carneiro. 0 reordenamento no mundo do trabalho e a precarização do trabalho do professor de educação física: mediações da mercadorização da cultu- 
ra corporal. Dissertação Universidade Federal Fluminense - Educação, 2009.

DIAS, Fernanda Braga Magalhães; TEXEIRA, David Romão. Formação de professores de educação física: a atualidade do embate político. Revista Motrivivência, ano XXII, n. 35, p. 184-201, 2010.

DIAS, Graziany Penna Empreendedorismo e educação: o Sebrae na escola. 2006. Dissertação (Mestrado em Educação)-Universidade Federal Fluminense, Niterói., 2006.

eMEC. Disponível em: <www.emec.mec.gov.br>. Acesso em: 12 jun de 2017.

FALCÃO, Jorge Tarcísio da Rocha; RÉGNIERE, Jean-Claude. Sobre os métodos quantitativos na pesquisa em ciências humanas: riscos e benefícios para o pesquisador. Revista Brasileira de Estudos Pedagógicos, Brasília, v. 81, n. 198, p. 229-243, 2000.

FERNANDES, Anoel. A renovação na Educação Física escolar: desafios e perspectiva, Rio Claro, Brasil, Revista Digital - Buenos Aires - Año 14 - № 133, 2009.

FRIGOTTO, Gaudêncio. O enfoque da dialética materialista histórica na pesquisa educacional. In: FAZENDA, I. (Org.). Metodologia da pesquisa educacional. 7. ed. São Paulo: Cortez, 2001. p. 81.

KOSIK, K. Dialética do concreto. Paz e Terra, Rio de Janeiro, 1976

LEMOS, Lovane Maria; VERONEZ, Luiz Fernando Camargo; MORSCHBACHER, Márcia; BOTH, Vilmar José. As contradições do processo de elaboração das diretrizes curriculares nacionais dos cursos de formação em Educação Física e os movimentos de resistência à submissão ao mercado. Porto Alegre, v. 18, n. 03, p. 27-49. 2012.

NETO, Samuel de Souza; ALEGRE, Atilio de Nardi; HUNGER, Dagmar; PEREIRA, Juliana Martins. Formação Do Profissional De Educação Física No Brasil: Uma História Sob A Perspectiva Da Legislação Federal No Século Xx. Revista Brasileira Ciência Esporte, Campinas, v. 25, n. 2, p. 113-128, 2004.

NOZAKI, Hajime Takeuchi. Educação Física e reordenamento no mundo do trabalho: mediações da regulamentação da profissão. 383f. Tese (Doutorado em Educação)Universidade Federal Fluminense, 2004.

NOZAKI, Hajime Takeuchi. O mundo do trabalho e o reordenamento da Educação Física Brasileira. Revista da Educação Física/uem 10(1), 1999.

NOZAKI, Hajime Takeuchi. Trabalho e educação na atualidade: mediações com a Educação Física brasileira. Santa Maria. v. 40, n. 1, p. 183-200, 2015.

RODRIGUES, Lionel dos Santos Feitosal. MNCR: 10 anos na luta pela regulamentação do trabalho. Feira de Santana, Bahia, UEFS Editora, 2011.

SILVA, Ana Márcia; BEDOYA, Victor Molina. Formação Profissional em Educação Física na América Latina Encontros, Diversidades e Desafios. Jundiaí, São Paulo. Paco Editorial, 2015.

SILVA, Ana Márcia; NICOLINO, Aline da Silva; INÁCIO, Humberto Luís de Deus; 
FIGUEIREDO; Valéria Maria Chaves. A formação profissional em Educação Física e o processo político social. Goiania, Goiás, Revista Pensar a prática v.12, n. 2., 2009.

SILVA, Osni Oliveira Noberto; SOUZA, Cláudio Lucena. Disposições legais em Educação Física: ingerências do CONFEF na tentativa de restrição profissional. Revista Digital, Buenos Aires, ano 14n. 135, 2009

TURATO, Egberto Ribeiro. Tratado da metodologia da pesquisa clínico-qualitativa: construção teórico-epistemológica, discussão comparada e aplicação nas áreas da saúde e humanas. 2. ed. Petrópolis: Vozes. 2003.

VENTURA, Paulo Roberto Veloso. A Educação Física e sua constituição histórica: desvelando ocultamentos. 2010. 206 p. Tese de Doutorado (Doutorado em Educação), Pontifícia Universidade Católica de Goiás, Goiânia. 2010. 